\title{
Identification of pathogens from blood culture bottles in spiked and clinical samples using matrix-assisted laser desorption ionization time-of-flight mass-spectrometry analysis
}

\author{
Simone Konnerth, Gisela Rademacher, Sebastian Suerbaum, Stefan Ziesing, Ludwig Sedlacek \\ and Ralf-Peter Vonberg ${ }^{*}$
}

\begin{abstract}
Background: Blood stream infections significantly contribute to mortality. An early most appropriate antimicrobial therapy is crucial for a favourable outcome of the patient. Matrix-assisted laser desorption ionization time-of-flight mass spectrometry (MALDI-TOF MS) may speed up the diagnostic of causative micro organisms.

Findings: MALDI-TOF MS using the SARAMIS database was applied to 37 spiked blood culture samples. Identification rates of spiked samples were as follows: The species level was determined in 16 of 21 (76.2\%) Gram negative bacteria and in 11 of 13 (84.6\%) Gram positive bacteria. Genus level only was determined in additional 2 Gram negative and for the 2 Gram positive strains. Yeast species could not be identified.

MALDI-TOF MS was also compared to cultured-based results in standard routine diagnostic. Identification rates of patient samples were as follows: The species level was determined in 41 of 47 (87.2\%) Gram negative bacteria and in 63 of 123 (51.2\%) Gram positive bacteria. Genus level only was determined in additional 2 Gram negative bacteria. Once again no yeasts were identified.

A prolonged incubation of $\mathrm{BC}$ bottles for 16 hours after primary positive alert did not influence the concentration of bacteria and identification rates.
\end{abstract}

Conclusions: The SARAMIS database used in our experiments mainly confirms previous findings that were obtained with the MALDI-TOF MS BRUKER system by others.

Keywords: Mass spectrometry, Blood culture, Bloodstream infection

\section{Findings}

\section{Background}

Blood stream infections significantly contribute to mortality on intensive care units and any delay in appropriate antimicrobial therapy independently increases the risk for a fatal course of disease [1]. That is the reason why the recently published International Guidelines for Management of Severe Sepsis and Septic Shock recommend "early administration of broad-spectrum antimicrobials [...], and reassessment of antimicrobial therapy daily for de-escalation, when appropriate" [2].

\footnotetext{
* Correspondence: Vonberg.Ralf@MH-Hannover.DE

Institute for Medical Microbiology and Hospital Epidemiology, Hannover Medical School, Carl-Neuberg-Str. 1, D-30625 Hannover, Germany
}

Changes in antibiotic therapy are mainly based on the microbiological findings from blood cultures (BC). Therefore, rapid identification of pathogens in the laboratory is important to guide treatment of the patient as early as possible. For this purpose, matrix-assisted laser-desorptionionization time-of-flight mass-spectrometry (MALDI-TOFMS) applied directly to positive BC broths represents a promising approach [3-8]. In this study we report results from spiked and clinical samples.

\section{Methods}

Blood samples $(10 \mathrm{~mL}$ each) of a healthy volunteer were spiked with $200 \mu \mathrm{L}$ of a suspension of microorganisms (McFarland 0.5) and transferred into BC bottles (BACTEC 
Plus-Aerobic/-Anaerobic, BD, Heidelberg, Germany). Bottles were incubated at $37^{\circ} \mathrm{C}$ in an automat (BACTEC FX, BD) until reported positive. The same procedure was applied to BC bottles (BACTEC Plus-Aerobic and -Anaerobic and PEDS Plus, BD) from the standard microbiological diagnostic, and results were compared to parallel culture-based testing by certified diagnostic standard operation procedures.

Preparation of pathogen proteins from positive $\mathrm{BC}$ bottles was performed as described previously [9]. In brief, sterile syringes were used to transfer $1.5 \mathrm{~mL}$ from positive $\mathrm{BC}$ bottles into gel-containing tubes (Vacutainer SST II, $\mathrm{BD})$. After centrifuging at $3.000 \mathrm{~g}$ at room temperature (RT) for $10 \mathrm{~min}$ the supernatant was discarded. The remaining pellet on the surface of the gel was resuspended with $1.3 \mathrm{~mL}$ of sterile water. A second centrifugation step in a new sterile tube at $13.000 \mathrm{~g}$ at RT was performed for $1 \mathrm{~min}$. Once again, the supernatant was discarded. Of the remaining pellet $0.5 \mu \mathrm{L}$ were spotted with sterile pipette tips in duplicates $(0.5 \mu \mathrm{L}$ each) onto a FlexiMass MALDI target (Shimadzu Biotech, Basel, Switzerland) for further use.

The mass spectrometer (AXIMA Assurance, Shimadzu) equipped with a $337 \mathrm{~nm}$ nitrogen laser and a maximum pulse rate of $50 \mathrm{~Hz}$ at $220 \mathrm{~V}$ was used for analysis. Spectra were recorded in positive linear mode in the range of 2 to $20 \mathrm{kDa}$. Data were automatically acquired using the database SARAMIS software 4.09 (AnagnosTec, Potsdam, Germany). Alpha-cyano-4-hydroxycinnamic acid (Alphy Cyano, bioMerieux, Nürtingen, Germany) served as matrix coverage $(1 \mu \mathrm{L})$. Identification of pathogens was undertaken with and without of $0.5 \mu \mathrm{L}$ using $25 \%$ formic acid. Protein preparation was repeated $16 \mathrm{~h}$ after the primary positive alert in order to check for a potential influence of accidentally prolonged incubation of BC bottles.

The study on clinical samples was approved by the institutional ethics committee and the ethics committee waived the need for written informed consent from the blood donor (Ethic Committee Document No. 2074-2013).

\section{Results and discussion}

A total of 37 spiked BC samples (34 bacteria and 3 yeasts) were tested as described. No false positive results were observed. Identification of species was possible for 16/21 (76.2\%) Gram negatives, additional 2 (9.5\%) strains were correctly identified on genus level only, and the remaining $3(14.3 \%)$ isolates were not identified at all. With respect to Gram positives the species of 11/13 (84.6\%) test organisms could be determined by MALDITOF-MS directly from the $\mathrm{BC}$ bottles, while only genus level was correctly ascertained for the remaining 2 (15.4\%). None of the 3 yeasts could be identified in spiked samples in our approach.
A total of $180 \mathrm{BC}$ bottles reported positive from standard microbiological diagnostic were also tested, thereof 120 aerobic, 52 anaerobic, and 8 pediatric BC probes. Parallel subculture on solid media in microbiological diagnostic revealed monomicrobial growth from 161 bottles and polymicrobial growth from 14 BC bottles. The remaining 5 samples did not show growth of any pathogen despite the previous positive alert of the $\mathrm{BC}$ automate. MALDI-TOF-MS analysis was then applied to all of the microorganisms from conventional sub-cultivation in order to check for its general ability of identification. The following pathogens were identified by MALDI-TOF-MS after conventional in-between growth on solid media in routine diagnostic processing from $\mathrm{BC}$ of patients: Bacteroides fragilis $(\mathrm{n}=2)$, Bacteroides thetaiotaomicron, Citrobacter spp. $(\mathrm{n}=2)$, Clostridium $\mathrm{spp}(\mathrm{n}=3)$, Enterococcus faecalis $(\mathrm{n}=8)$, Enterococcus faecium $(\mathrm{n}=4)$, Enterobacter cloacae, Escherichia coli $(\mathrm{n}=22)$, Haemophilus influenzae $(\mathrm{n}=3)$, Klebsiella oxytoca, Klebsiella pneumoniae $(\mathrm{n}=6)$, Lactococcus garviae, Micrococcus luteus, Moraxella osloensis, Morganella morganii, Pantoea agglomerans, Proprionibacterium acnes $(\mathrm{n}=8)$, Proteus mirabilis, Pseudomonas aeruginosa $(\mathrm{n}=4)$, Staphylococcus aureus $(\mathrm{n}=24)$, Staphylococcus capitis $(\mathrm{n}=6)$, Staphylococcus epidermidis $(\mathrm{n}=39)$, Staphylococcus haemolyticus $(\mathrm{n}=7)$, Staphylococcus hominis $(\mathrm{n}=13)$, Staphylococcus saccharolyticus, Stenotrophomonas maltophilia, Streptococcus agalactiae, Streptococcus mitis $(\mathrm{n}=2)$, Streptococcus salivarius, Streptococcus spp. $(\mathrm{n}=4)$, Candida albicans $(\mathrm{n}=3)$, and Candida glabrata $(\mathrm{n}=3)$. This panel of clinical strains seems quite representative, as the rather large proportion of Gram positive bacteria matches the most frequent pathogens from $\mathrm{BC}$ bottles as reported from the German National Reference Centre for the Surveillance of Nosocomial Infections (KISS) [10]. Noteworthy, just like others [11] we were also able to identify several yeasts after grown on solid media by MALDI-TOF-MS analysis.

However, when performed directly from positive $\mathrm{BC}$ samples, MALDI-TOF-MS correctly identified the species in $41(87.2 \%)$ and the genus only in $2(4.3 \%)$ of the 47 Gram negatives - among them several species that usually present with highly resistant antimicrobial profiles - compared to 63 (51.2\%) identifications on species level of the 123 Gram positives. Once again all yeasts remained unidentified. Identification of yeasts via mass spectrometry relies on rather few peaks only, which may disturb the microbiological diagnostic process [12]. Whether the failure of yeast identification directly from the $\mathrm{BC}$ bottles was due to the different growth conditions in the bottle compared to the solid media [13] remains unclear in our study.

A prolonged incubation of $\mathrm{BC}$ bottles after the primary positive alert did not influence the concentration 
of bacteria as shown in Figure 1. The mean number of colony forming units in the $\mathrm{BC}$ bottle at the time point of alert was $1.91 \times 10^{10}$ and $1.89 \times 10^{10}$ at $16 \mathrm{~h}$ thereafter respectively. No changes in identification rates were observed either.

At present there is a considerable variation in identification rates of pathogens directly from $\mathrm{BC}$ bottles by MALDI-TOF-MS. For example Christner et al. achieved an overall identification rate of $87 \%$ [14], while others report difficulties especially in the identification of Gram positive bacteria, fungi and pathogens from polymicrobial samples [15-18]. These discrepant findings may be due to variations in the diagnostic protocol including the $\mathrm{BC}$ bottle used $[9,19]$, the preparatory methods for extraction of pathogens [20,21], and the type of mass spectrometer and applied database [8,9,22-24].

Further studies should be undertaken in order to determine optimal conditions for the application of MALDITOF-MS technology for the benefit of patients suffering from septicemia $[25,26]$. Such future approaches may for example focus on limiting the potential loss of pathogens during their extraction from the $\mathrm{BC}$ sample. One may also try subtracting interfering background peaks that are due to other patient's proteins [27]. In addition, a larger number on mass spectrum data - especially of yeasts - could

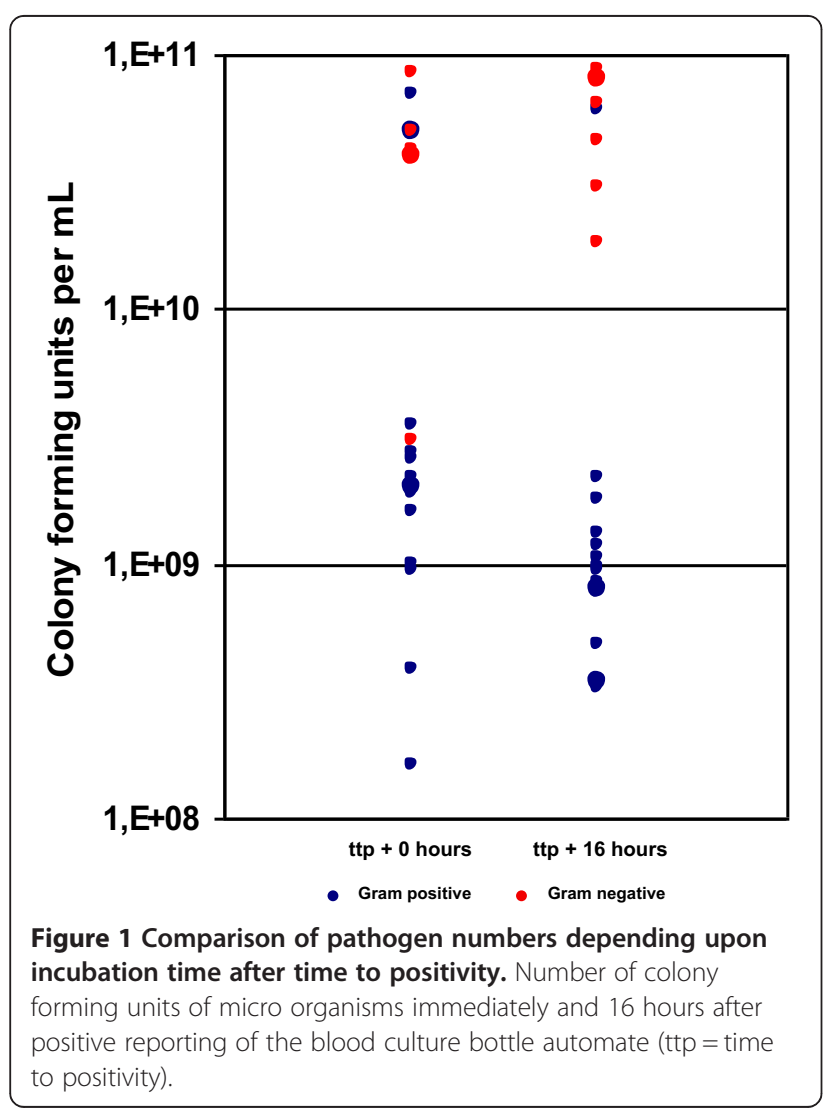

also improve the overall accuracy of species identification by MALDI-TOF-MS analysis.

\section{Competing interests}

The authors declare that they have no competing interest.

\section{Authors' contributions}

SK: Substantial contribution to conception of the study and performing laboratory work; GR: Substantial contribution to conception and design of the study; SS: Critical revision of the manuscript; SZ: Acquisition of data and technical support; LS: Analysis of data and supervision of the experiments; RPV: Analysis of data and drafting of the manuscript. All named individuals qualify as an author and have given final approval of the version to be published.

\section{Acknowledgements}

The authors would like to thank the Deutsche Forschergemeinschaft (DFG) for sponsorship of the Open Access Publication process.

Received: 10 March 2014 Accepted: 23 June 2014

Published: 27 June 2014

\section{References}

1. Retamar P, Portillo MM, Lopez-Prieto MD, Rodriguez-Lopez F, de Cueto M, Garcia MV, Gomez MJ, Del Arco A, Munoz A, Sanchez-Porto A, TorresTortosa M, Martin-Aspas A, Arroyo A, Garcia-Figueras C, Acosta F, Corzo JE, Leon-Ruiz L, Escobar-Lara T, Rodriguez-Bano J: Impact of inadequate empirical therapy on the mortality of patients with bloodstream infections: a propensity score-based analysis. Antimicrob Agents Chemother 2012, 56:472-478.

2. Dellinger RP, Levy MM, Rhodes A, Annane D, Gerlach H, Opal SM, Sevransky JE, Sprung CL, Douglas IS, Jaeschke R, Osborn TM, Nunnally ME, Townsend SR, Reinhart K, Kleinpell RM, Angus DC, Deutschman CS, Machado FR, Rubenfeld GD, Webb S, Beale RJ, Vincent JL, Moreno R: Surviving sepsis campaign: international guidelines for management of severe sepsis and septic shock, 2012. Intensive Care Med 2013, 39:165-228.

3. La Scola B, Raoult D: Direct identification of bacteria in positive blood culture bottles by matrix-assisted laser desorption ionisation time-offlight mass spectrometry. PLoS One 2009, 4:e8041.

4. Prod'hom G, Bizzini A, Durussel C, Bille J, Greub G: Matrix-assisted laser desorption ionization-time of flight mass spectrometry for direct bacterial identification from positive blood culture pellets. J Clin Microbiol 2010, 48:1481-1483.

5. Moussaoui W, Jaulhac B, Hoffmann AM, Ludes B, Kostrzewa M, Riegel P, Prevost G: Matrix-assisted laser desorption ionization time-of-flight mass spectrometry identifies $90 \%$ of bacteria directly from blood culture vials. Clin Microbiol Infect 2010, 16:1631-1638.

6. Stevenson LG, Drake SK, Murray PR: Rapid identification of bacteria in positive blood culture broths by matrix-assisted laser desorption ionizationtime of flight mass spectrometry. J Clin Microbiol 2010, 48:444-447.

7. Wuppenhorst N, Consoir C, Lorch D, Schneider C: Direct identification of bacteria from charcoal-containing blood culture bottles using matrixassisted laser desorption/ionisation time-of-flight mass spectrometry. Eur J Clin Microbiol Infect Dis 2012, 31:2843-2850.

8. Vlek AL, Bonten MJ, Boel CH: Direct matrix-assisted laser desorption ionization time-of-flight mass spectrometry improves appropriateness of antibiotic treatment of bacteremia. PLoS One 2012, 7:e32589.

9. Schmidt V, Jarosch A, Marz P, Sander C, Vacata V, Kalka-Moll W: Rapid identification of bacteria in positive blood culture by matrix-assisted laser desorption ionization time-of-flight mass spectrometry. Eur J Clin Microbiol Infect Dis 2012, 31:311-317.

10. Gastmeier P, Geffers C, Sohr D, Schwab F, Behnke M, Ruden H: Surveillance of nosocomial infections in intensive care units. Current data and interpretations. Wien Klin Wochenschr 2003, 115:99-103.

11. Wang W, Xi H, Huang M, Wang J, Fan M, Chen Y, Shao H, Li X: Performance of mass spectrometric identification of bacteria and yeasts routinely isolated in a clinical microbiology laboratory using MALDI-TOF MS. J Thorac Dis 2014, 6:524-533.

12. Chalupova J, Raus M, Sedlarova M, Sebela M: Identification of fungal microorganisms by MALDI-TOF mass spectrometry. Biotechnol Adv 2014, 32:230-241. 
13. Usbeck JC, Kern CC, Vogel RF, Behr J: Optimization of experimental and modelling parameters for the differentiation of beverage spoiling yeasts by Matrix-Assisted-Laser-Desorption/lonization-Time-of-Flight Mass Spectrometry (MALDI-TOF MS) in response to varying growth conditions. Food Microbiol 2013, 36:379-387.

14. Christner M, Rohde H, Wolters M, Sobottka I, Wegscheider K, Aepfelbacher M: Rapid identification of bacteria from positive blood culture bottles by use of matrix-assisted laser desorption-ionization time of flight mass spectrometry fingerprinting. J Clin Microbiol 2010, 48:1584-1591.

15. Szabados F, Michels M, Kaase M, Gatermann S: The sensitivity of direct identification from positive BacT/ALERT (bioMerieux) blood culture bottles by matrix-assisted laser desorption ionization time-of-flight mass spectrometry is low. Clin Microbiol Infect 2011, 17:192-195.

16. Ferreira L, Sanchez-Juanes F, Porras-Guerra I, Garcia-Garcia MI, Garcia-Sanchez JE, Gonzalez-Buitrago JM, Munoz-Bellido JL: Microorganisms direct identification from blood culture by matrix-assisted laser desorption/ionization time-offlight mass spectrometry. Clin Microbiol Infect 2011, 17:546-551.

17. Loonen AJ, Jansz AR, Stalpers J, Wolffs PF, van den Brule AJ: An evaluation of three processing methods and the effect of reduced culture times for faster direct identification of pathogens from BacT/ALERT blood cultures by MALDI-TOF MS. Eur J Clin Microbiol Infect Dis 2012, 31:1575-1583.

18. Nonnemann B, Tvede M, Bjarnsholt T: Identification of pathogenic microorganisms directly from positive blood vials by matrix-assisted laser desorption/ionization time of flight mass spectrometry. APMIS 2013, 121:871-877.

19. Romero-Gomez MP, Mingorance J: The effect of the blood culture bottle type in the rate of direct identification from positive cultures by matrixassisted laser desorption/ionisation time-of-flight (MALDI-TOF) mass spectrometry. J Infect 2011, 62:251-253.

20. Saffert RT, Cunningham SA, Mandrekar J, Patel R: Comparison of three preparatory methods for detection of bacteremia by MALDI-TOF mass spectrometry. Diagn Microbiol Infect Dis 2012, 73:21-26.

21. Gray TJ, Thomas L, Olma T, Iredell JR, Chen SC: Rapid identification of Gram-negative organisms from blood culture bottles using a modified extraction method and MALDI-TOF mass spectrometry. Diagn Microbiol Infect Dis 2013, 77:110-112.

22. Fothergill A, Kasinathan V, Hyman J, Walsh J, Drake T, Wang YF: Rapid identification of bacteria and yeasts from positive-blood-culture bottles by using a lysis-filtration method and matrix-assisted laser desorption ionization-time of flight mass spectrum analysis with the SARAMIS database. J Clin Microbiol 2013, 51:805-809.

23. Foster AG: Rapid identification of microbes in positive blood cultures by matrix-assisted laser desorption/ionisation time-of-flight (Maldi-Tof) mass spectrometry- (Vitek MS -bioMerieux.). J Clin Microbiol 2013, 51:3717-3719.

24. Jamal W, Saleem R, Rotimi VO: Rapid identification of pathogens directly from blood culture bottles by Bruker matrix-assisted laser desorption laser ionization-time of flight mass spectrometry versus routine methods. Diagn Microbiol Infect Dis 2013, 76:404-408.

25. Martiny D, Debaugnies F, Gateff D, Gerard M, Aoun M, Martin C, Konopnicki D, Loizidou A, Georgala A, Hainaut M, Chantrenne M, Dediste A, Vandenberg O, Van Praet S: Impact of rapid microbial identification directly from positive blood cultures using matrix-assisted laser desorption/ ionization time-of-flight mass spectrometry on patient management. Clin Microbiol Infect 2013, 19:E568-E581.

26. Huang AM, Newton D, Kunapuli A, Gandhi TN, Washer LL, Isip J, Collins CD, Nagel JL: Impact of rapid organism identification via matrix-assisted laser desorption/ionization time-of-flight combined with antimicrobial stewardship team intervention in adult patients with bacteremia and candidemia. Clin Infect Dis 2013, 57:1237-1245.

27. Klein S, Zimmermann S, Köhler C, Mischnik A, Alle W, Bode KA: Integration of matrix-assisted laser desorption/ionization time-of-flight mass spectrometry in blood culture diagnostics: a fast and effective approach. J Med Microbiol 2012, 61:323-331.

\section{doi:10.1186/1756-0500-7-405}

Cite this article as: Konnerth et al:: Identification of pathogens from blood culture bottles in spiked and clinical samples using matrix-assisted laser desorption ionization time-of-flight mass-spectrometry analysis. BMC Research Notes 2014 7:405.

\section{Submit your next manuscript to BioMed Central and take full advantage of:}

- Convenient online submission

- Thorough peer review

- No space constraints or color figure charges

- Immediate publication on acceptance

- Inclusion in PubMed, CAS, Scopus and Google Scholar

- Research which is freely available for redistribution 